Portland State University

PDXScholar

\title{
Using a Computer Program about Pediatric Hearing Evaluations to help Educate Parents
}

Jeanne E. Aleskus

Portland State University

Follow this and additional works at: https://pdxscholar.library.pdx.edu/open_access_etds

Part of the Speech and Rhetorical Studies Commons

Let us know how access to this document benefits you.

\section{Recommended Citation}

Aleskus, Jeanne E., "Using a Computer Program about Pediatric Hearing Evaluations to help Educate Parents" (1996). Dissertations and Theses. Paper 4957.

https://doi.org/10.15760/etd.6833

This Thesis is brought to you for free and open access. It has been accepted for inclusion in Dissertations and Theses by an authorized administrator of PDXScholar. Please contact us if we can make this document more accessible: pdxscholar@pdx.edu. 
THESIS APPROVAL

The abstract and thesis of Jeanne E. Aleskus for the Master of Science in Speech Communication: Speech and Hearing Science were presented May 20, 1996, and accepted by the thesis committee and the department. COMMITTEE APPROVALS:

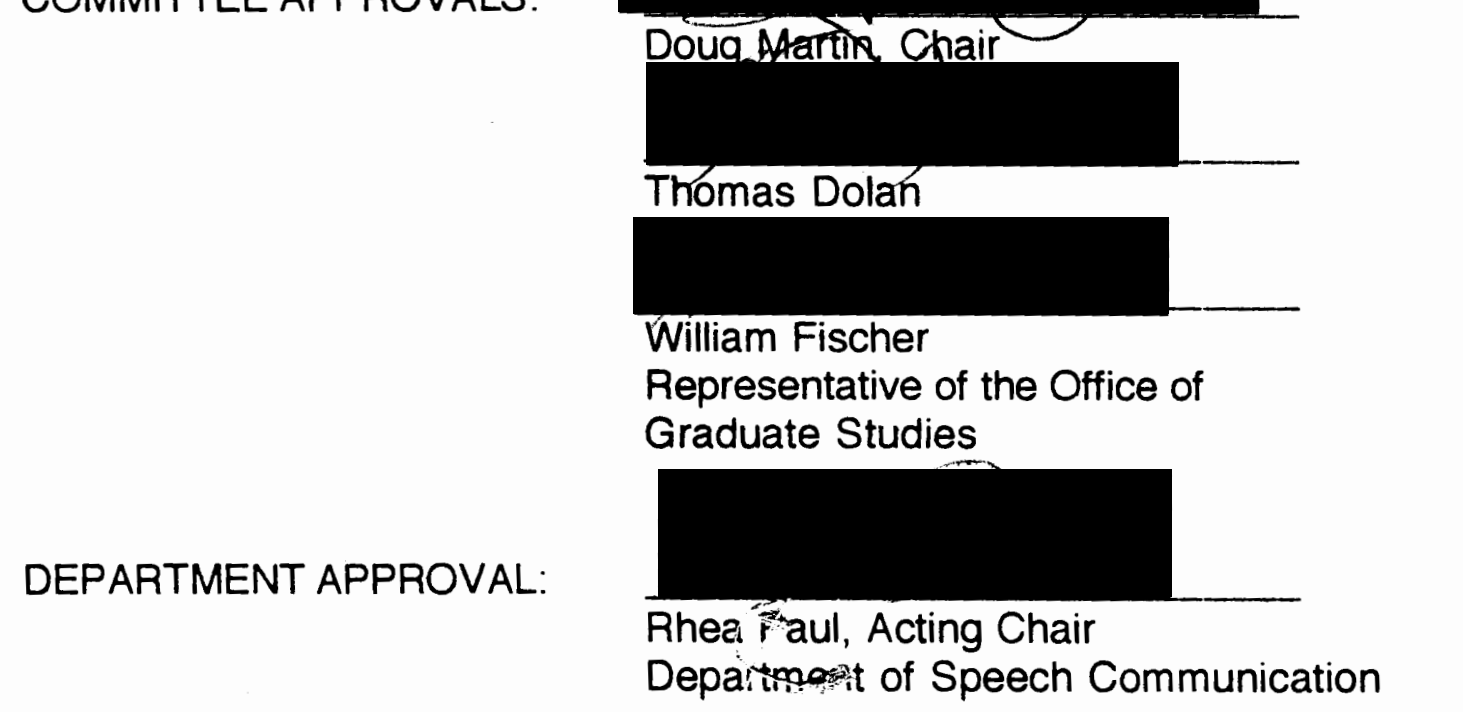

ACCEPTED FOR PORTLAND STATE UNIVERSITY BY THE LIBRARY By on 5 fawe 1996 


\begin{abstract}
An abstract of the thesis of Jeanne E. Aleskus for the Master of Science in Speech Communication: Speech and Hearing Science presented May 20, 1996.
\end{abstract}

Title: $\quad$ Using a computer program about pediatric hearing evaluations to help educate parents.

Hearing assessment techniques, and counseling for the pediatric population are different from those used on adults. Parents will often not have any prior knowledge of how their child's hearing will be assessed. Therefore, many questions may pertain to the mechanics of the evaluation. Audiologists may find the questions take away some of their counseling time and they have less time to discuss the diagnosis and prognosis of the child. The purpose of this study was to determine if a computer program developed with information about pediatric evaluations could be used to educate individuals about this process.

Twenty subjects were involved with this study. Eighteen volunteers were attending Portland State University, and two were volunteers from the general population. Ten subjects were selected to come to Portland State University to view a computer program about pediatric hearing evaluations. The other ten were part of the control group and did not view the computer program. Immediately following each subject answered the questionnaire. The questions on the questionnaire covered information about: 
otoscopy, behavioral observation audiometry, visual reinforcement audiology, play audiometry, tympanometry and speech testing. The results were tabulated and percentages calculated.

The results of this study indicated that, in general, the computer program did educate the participants about pediatric evaluations. In some areas such as tympanometry, otoscopy, and testing procedures the computer program was extremely strong.

The information obtained in this study would indicate that a computer program might be used to educate parents about the techniques used in a pediatric evaluation prior to their child's appointment. In some areas such as the information regarding speech testing, and some questions relating to different behavioral techniques, there appears to be a need for further development and expansion, so the parents will be able to retain the information in these areas. 
USING A COMPUTER PROGRAM ABOUT PEDIATRIC HEARING

EVALUATIONS TO HELP EDUCATE PARENTS

by

JEANNE E. ALESKUS

A thesis submitted in partial fulfillment of the requirements for the degree of

\author{
MASTER OF SCIENCE \\ in \\ SPEECH COMMUNICATION: \\ SPEECH AND HEARING SCIENCE
}

Portland State University

1996 


\section{ACKNOWLEDGMENTS}

To Dr. Martin as my thesis director for his assistance and encouragement.

To my father Joseph Peter Aleskus Jr., my mother Barbara Lee Aleskus and my grandfather John M. Shank, for all their support. Without them I could not have accomplished this dream.

To the special friends who kept me sane during this exhausting process and told me that there would be light at the end even of this tunnel. 
TABLE OF CONTENTS

Page

ACKNOWLEDGMENTS .............................................................. ii

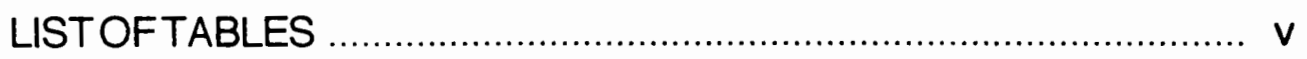

CHAPTER

1 INTRODUCTION AND STATEMENT OF PURPOSE.. 1

II REVIEW OFTHE LITERATURE ……….................... 5

Pediatric Assessment Procedures .................. 5

Counseling the Parent ..................................... 9

Information Transfer ........................................ 13

III METHODS AND PROCEDURES ….......................... 16

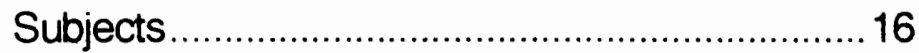

Instrumentation .................................................. 17

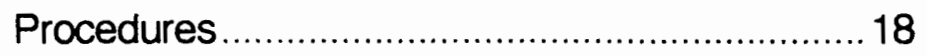

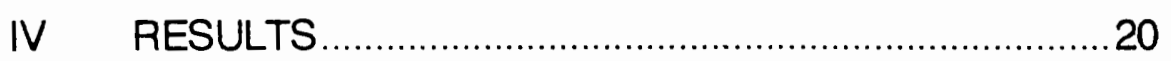

$\checkmark \quad$ DISCUSSION AND IMPLICATIONS ........................ 28

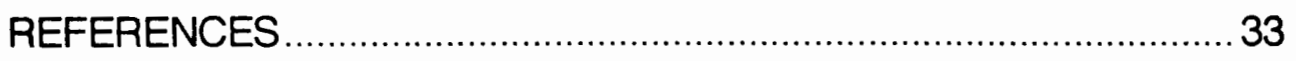

APPENDIX

A Computer format outline ............................................. 36

B Example screen from the computer program.......... 40

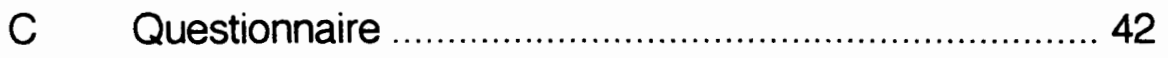

D ConsentForm ......................................................... 47 


\section{LIST OF TABLES}

TABLE

1 Questions answered correctly by experimental 21 group with the frequency distribution for each response option

II Questions where the experimental group scored 24 $30 \%$ or greater than the control group with the frequency distribution for each response option

III Questions where $70 \%$ or more of the total number.....25 of subjects answered incorrectly with the frequency distribution for each response option

IV Questions where the rating scores for both groups.....26 were $80 \%$ or above with a $10 \%$ difference or less between the groups with the frequency distribution for each response option

V Questions where the responses of both groups met...27 none of the previous criteria with the frequency distribution of each response option 


\section{CHAPTER I}

\section{INTRODUCTION}

The hearing assessment of the pediatric client is very different than that for the adult. Because of these differences, the audiologist must often take more time with a pediatric patient. However, it is usually not the patient that requires the time but the parents of these children. Most hearing-impaired children are born to hearing parents who likely have little prior knowledge about hearing impairment. (Rushmer, 1994) Parents will often have no prior knowledge of how their child's hearing will be assessed and, therefore, may have many questions about the mechanics of the assessment. When taking the time to answer questions about the fundamentals involved with the assessment, the audiologist may be left with less time to discuss the results of the evaluation.

It is often the case that a parent who is seeking a pediatric evaluation, whether from self referral or physician referral, enters the situation with some amount of stress. F. Martin (1994) states that parents generally come to their child's initial diagnostic experience filled with hopes, no matter how realistic or unrealistic, that their worst fears will not be confirmed. F. Martin also reports that dealing with difficult information is sometimes impossible under the stress of the diagnostic situation and the revelation of a serious hearing difficulty.

One of the major differences between assessing children and adults has to do with the fact that children are assessed in a more indirect fashion than 
adults. Adults can give direct feedback that allows the audiologist to determine hearing sensitivity more objectively. The commonly used pediatric techniques, behavioral observation audiometry and visual reinforcement audiometry, rely on the child showing some behavior such as a head nod, head turn, or placing a block in a box in response to sound. Since parents may not understand some of these basic differences they can often become confused with the responses that their child is exhibiting and in turn wonder if the assessment is valid. If information were made available to the parent prior to the assessment, some of the worry and stress about what will be occurring during the visit may be relieved.

One of the most effective ways of providing such information would be through face to face counseling. However, this is a time consuming process, and as F. Martin and Clark report "Audiologists often feel uncomfortable in their role as patient counselor" $(1994$, p.3). To further describe the audiologist's fear, F. Martin and Clark explain that, "the feeling that they must fill a counseling void by assuming the responsibilities of a professional counselor makes them even more insecure"(1994, p.5). Giving the parent a pamphlet to read prior to the assessment could be another way to present all relevant information. Although this may be an efficient manner for the audiologist, the burden of processing novel information is now placed on the parent. If they take the pamphlet there is no guarantee that they will read it. Some parents may be illiterate, have poor reading skills, or may not have time to read the pamphlet. In these instances using a written pamphlet for information transfer could prove unsuccessful.

One method of information transfer that has become popular is multimedia. Multimedia implies that information is given in several different forms. Rodriguez and Rowe (1995) state "some people see multimedia as the effort to 
combine text, graphics, images, video, and audio in computers to convey enriched information to users" (p. 20). It may be verbal information, movies, printed text, or pictures or it could be the use of some or all these media combined via a computer program. One reason that multimedia is so effective is that it relays information in a manner that is time efficient for the clinician and yet more interesting for the client. Krendl and Lieberman (1988) explain that research on academic motivation and computers found that in most instances the computer was highly motivating when used as a tool in the education process. They went on to discuss that some of the computers attractiveness comes from its ability to be interactive, precise and consistently give the individual encouragement through the use of text, movies or narration. It also overcomes some barriers that other forms of communication may present. For instance, parents who may not know how to read could have the program actually talk to them and give them the information verbally, supplemented with pictures and graphs. Multimedia can also overcome language barriers. In this instance the parent could select from a main menu the language they would need the program to use in order for the information to be conveyed. Therefore, multimedia can bridge gaps in information transfer due to illiteracy or language barriers.

There are many differences between the pediatric hearing evaluation and an adult evaluation, and these differences may not be obvious to the naive observer. Recognizing the different techniques employed in assessing a pediatric patient and the need to educate the parent regarding these techniques, a multimedia program discussing and demonstrating pediatric assessment techniques has been developed by $D$. Martin (personal communication, 1996). The purpose of this program is to provide a brief 
introduction to the evaluation process prior to the actual testing. Through the use of a self-directed interactive program, it is hoped that important information can be provided to the parent without the demands of considerable time or commitment on the part of the clinician.

\section{STATEMENT OF PURPOSE}

While the approach suggested by F. Martin may prove beneficial to both the parent and the clinician, no study of the effectiveness of the program has yet been undertaken. This study provided an initial investigation of the effectiveness of this program in conveying information regarding pediatric audiological assessment techniques to a general audience. This was accomplished by presenting the program to a group of young adult subjects and comparing their subsequent performance on a brief test regarding pediatric assessment techniques with the subjects who did not view the program. The purpose of this study was to facilitate the refinement of both the multimedia program and the assessment tool for future use with parents. 


\section{CHAPTER II}

\section{REVIEW OF THE LITERATURE}

The purpose of this study is to determine the effectiveness of the interactive multimedia computer program authored by D. Martin (personal communication, 1996), on conveying information regarding techniques involved in a pediatric evaluation. In preparing to undertake this study issues relating to pediatric assessment, parental counseling, and multimedia education were considered of prime importance. Therefore, the literature relating to these three areas will be reviewed.

\section{Pediatric Assessment Procedures}

Standard audiological procedures for pure tone audiometry with adults require that the adult raise a hand or press a button in response to hearing a tone. The procedures for children differ and rely more on what behaviors the audiologist observes. Therefore, the child is not responsible for directly indicating that they heard the sound. There are many different techniques used with different age appropriate normative data.

Hayes and Pashley (1991) state that the "diagnostic evaluation of infants and young children requires a test battery approach that combines behavioral measures of auditory sensitivity and physiologic measures of middle ear 
function"(p. 260). One of the first techniques that is different in a pediatric evaluation than an adult evaluation is behavioral observation audiometry (BOA). BOA does not require that the child be able to condition to a task. BOA looks at the child's overt behavior when sound is present. Behaviors that would be considered responses to sound may include eye blinking, arousal from sleep, or movement of limbs. Hayes and Pashley (1991) state that since this is not a conditioned or a reinforced behavior the responses habituate over time. Another shortcoming of BOA relates to the observation that infants do not possess the maturity to provide overt behavioral responses at threshold levels. Thus, we can expect an infant's true threshold to fall at a level well below observed behavioral threshold. Silman and Silverman (1991) state that as BOA can underestimate hearing sensitivity because the response is suprathreshold, it is, recommended as a screening technique only.

A second technique used in children as young as 6 months of age is Visual Reinforcement Audiometry, (VRA). VRA uses a lighted toy that is paired with the stimulus sound so that a head turn towards the light is elicited from the child following the presentation of a sound. Eventually the child is conditioned to turn his head in response to sound and then is reinforced by seeing the object displayed. The reinforcement of the child's head turning response helps reduce the habituation of this behavior. Since the behavior does not habituate as quickly, Friedrich (cited by Hayes and Pashley, 1991) report that precise information can be obtained from children with a developmental age as young as 6 months. However, there exists some controversy regarding the age at which VRA will elicit consistent responses. Muir and Field (cited by Moore, Thompson, Folsom, 1992) stated that "many newborns will turn to sound at birth 
and during the 1st month, perform poorly during 2 nd and 3rd mo., and localize well during the 4th mo." (p. 187) The theories concerning why there is a change during the first four months of infancy suggest that during the first month the response is reflexive but during the second to third month coordination between the sensory and motor functions take place inhibiting the reflexive behavior. At about four months, the response reappears indicating the emergence of intentional or voluntary responses. (Moore, et. al. 1992) However, VRA can be used on children who are infants and up to approximately three years of age.

A more advanced audiological technique for children is play audiometry. The child is conditioned in play audiometry to respond to sound by placing a block in a box, a peg in a peg board, or other activities that can be structured to complete the task. Play audiometry can be done under headphones and in soundfield. A more demanding task for the child may be listening while under headphones, due to possible fear the child may have. (Hodgson 1994) However, this technique provides the audiologist the most information about the presence or absence of a hearing loss. Play audiometry can be used on children whose cognitive skills allow them to condition well to a voluntary response task. The age in which a child can be conditioned to this type of task may vary. It could occur at two years of age for some children, or up to four years for others based on their cognitive development. Therefore, there are certain criteria that need to be met for each child. The child must condition well to a specific task, they must be able to follow instructions, and have the necessary voluntary motor control to perform the task. Often a child will condition to play audiometry in soundfield but is not willing to wear headphones. In such instances the results obtained reflect thresholds of the 
better ear only. Thus soundfield testing may miss any asymmetries in the child's hearing.

There are many differences between testing children and adults, however, there are also some testing procedures that are used on both populations. An immittance battery is used in adults but it is especially necessary in children to determine the status of the middle ear. Hayes and Pashley (1991) discuss the importance of evaluating middle ear status during diagnostic audiologic evaluations due to the prevalence of Otitis Media in this population. Jerger (cited by Hayes and Pashley 1991) states that the use of tympanometry can provide clinical predictions of middle ear function and, in cases of normal middle ear function, acoustic reflexes can predict the presence or absence of sensorineural hearing loss.

Speech testing is used across all ages. A common speech measure used with all ages is the Speech Reception Threshold (SRT). This test determines the lowest level at which simple speech signals can be recognized. However, the measure of speech awareness threshold, (SAT) may be easier if their are language limitations or cognitive delays (Hodgson 1994). This measure assesses the level at which the child can first detect the presence of speech. It does not give evidence of whether the child understands the speech. However, there is a direct correlation between the pure tone thresholds and the SAT. The importance of this correlation is that it can alert the audiologist that the test results may not be accurate if the two scores do not correlate well to one another.

Speech discrimination is a speech test which is also used on several different age groups. The test is a list of monosyllabic words that are phonetically balanced for all speech sounds. The frequencies of the hearing 
loss will affect the accuracy with which these sounds can be recognized, and therefore it may give us information regarding the hearing loss.

It is important when assessing children to remember that a test battery is the best approach. (Hayes and Pashley, 1991) Therefore, the more information obtained the clearer that the picture can be when presented with a child who is suspected of having a hearing loss. The audiologist must decide during the course of the evaluation which techniques will be most appropriate for a given child, based on age, cognitive ability and motoric development. Thus, it is difficult to predict ahead of time the exact course of events that will transpire during the pediatric evaluation.

The differences in techniques and the processes involved in completing a pediatric evaluation are likely to be, at least, unfamiliar and, more likely, confusing to the naive observer. Subsequent counseling about the diagnosis and prognosis may be complicated by the parent's confusion regarding the evaluation process. Unfortunately the time spent discussing the procedures may take away from the time spent on discussing the results. It may also be difficult for the parent to understand the information about the procedures and and then also be receptive to the diagnostic information at one time. If the information regarding the procedures was available prior to the appointment the parent may require less counseling in this area and be more receptive to information regarding the diagnosis and treatment options.

Counseling the Parent

Many professions such as psychology, psychiatry, and social work are based on the study and practice of counseling. Audiologists, on the other hand, do not 
focus on counseling because their educational background often involves limited exposure to this area. Therefore, they do not have in depth training in counseling issues (Clark 1994). Yet, counseling patients and family is a very important part of the audiologist's role. Clark (1994) states:

To be most effective in serving patients and their families, audiologists must become adept not only in the diagnosis of auditory disorders and the rehabilitative management of these disorders, but also in the more elusive area of successfull patient-professional relationships that may be built and maintained through the art of counseling. (p.2-3)

In the field of audiology two types of counseling are used. The first type, which has been more common, is information giving or content counseling ( $F$. Martin, George, O'Neal, and Daly 1987). In content counseling the audiologist provides the parents with written or verbal descriptions of the hearing loss, the severity of the loss, or pathology information. F. Martin et al. state that content counseling relies on the information or facts available to the clinician. It does not take into consideration the parents feelings at the time of discussion.

The second type of counseling used is affect counseling. Luterman (1979) describes affect counseling as counseling that helps the patient cope with the many emotions and feelings at the time of the evaluation.

F. Martin et al. (1987) reported that parents have said that content counseling is ineffective as it, "doesn't meet the needs of the parents at the time of diagnosis" (p. 27). Luterman reports that it is important to remember that the parents' emotional needs must be met before they will be able to comprehend the factual information.

In order for the audiologist to deal with the emotions of the parents they must be familiar with the common stages the parents go through when they hear their 
child has a hearing impairment. Luterman (1979) outlines the typical emotional responses from parents when they receive information that their child has a hearing impairment. These stages resemble the stages of grief as outlined by Kubler-Ross (1969).

The first stage is the mourning reaction, which can often be characterized by a feeling of relief for some parents. In these instances, the parents, and especially the mother, have been trying to get answers for their child's behavior and now the explanation is that they have a hearing impairment. Even though the parents may be relieved they also start to mourn the fantasy that their child will be like any other child.

The second stage is shock. A state of shock allows the parent to gather themselves and feel their initial stage of mourning. It is not advisable to give information to parents during this time. Luterman (1979) reports that in this stage many parents remember little, if any initial information the clinician said that related to their child although they might remember some other insignificant statement.

The third stage is recognition. During recognition many different emotions are evident. The parent finally realizes what this diagnosis means to them, their family, and their child. Feelings of being overwhelmed with information occur. The parents may also experience anger. The anger can be directed toward the clinician and even, at times, the child or themselves. It is important that the parents be able to express this anger in a positive manner. It isn't uncommon at this stage for parents to want to bargain away the problem, or experience feelings of guilt that can lead to resentment of the child.

The fourth stage is denial. Denial occurs in an attempt to deal with all the emotions that occur during recognition. Denial can take many forms. Parents 
may become too involved in work, committees etc. to avoid feeling the pain of their loss.

The fifth stage is acknowledgement where parents accept and embrace their loss and what the future may bring. An example that Luterman used for acceptance was when the child's hearing aids were worn to school on the outside of clothing instead of under hats, bows etc. Since wearing hearing aids is a public acknowledgement of impairment it tells the audiologist that the parents have fully accepted the situation and have begun taking constructive actions to address the hearing loss.

Luterman's final, or sixth stage is called constructive action. This stage is where the parents restructure their lives according to the new demands of their child and reexamine their values as well. Many times individuals realize how lucky they are with the things they have instead of focusing on what their child doesn't have, in this case normal hearing .

Since there are many parental emotions that an audiologist must deal with it becomes important to allow the proper amount of time for such counseling sessions. F. Martin (1987) states that informational counseling is not sufficient in these counseling sessions and that both counseling techniques need to be used to address all issues. By providing some content or factual counseling prior to the evaluation to describe the mechanics and basic principles involved with the evaluation it may be possible to eliminate a significant portion of the factual or content information that is necessary following a diagnostic session. Using a precounseling tool may also allow the parent to understand the procedures they see their child is participating in so they can ask more educated and directed questions about the diagnosis and not the protocol that determined it. Although audiologists may feel uncomfortable in being a 
counselor in these situations, it is necessary. The use of such a tool may help to initiate a more effective counseling session.

\section{INFORMATION TRANSFER}

Many different mediums are now available to allow for information transfer. There are traditional methods such as verbal or written communication, as well as the new multimedia, and even more specific hypermedia. One problem with some of the traditional forms of communication is that some individuals may not be able to interpret the information given. Literacy is a significant issue when trying to determine the method of information transfer to use. Weiss et al (1995) reports that more than 25 million American adults lack basic reading skills and an additional $\mathbf{4 5}$ million have rudimentary skills that would not be considered adequate to participate fully in society. It is also noted that several "subgroups" of society show high incidence of illiteracy. Some of these subgroups include minority groups, which are comprised largely of young adults.

Another traditional form of giving information is through the use of verbal transmission, such as speech, or lectures. In instances where English is not the primary language, this communication technique would be unsuccessful without the use of an interpreter.

With the expanding capabilities of computer technology, a new medium has emerged for transferring information. Multimedia, as defined in the article by McKerlie and Preece (1993), is an umbrella term for integrating elements, such as text, graphics, video, sound and pictures in one application that can then be presented to the user. 
Multimedia is oftentimes referred to as a passive manner of information acquisition. It does not require the user to choose. Hypermedia on the other hand may be considered an active means of information acquisition. McKerlie et al. (1993) defines hypermedia as having two characteristics; one being that it is a network representation of information and that it relies on reader participation. It is, therefore, a specialized interactive form of multimedia. One reason that this format is so appealing is that since it can provide the user with choices it can also give choices on how the information is relayed, such as if the user would prefer text, narration (speech), movies or photographs. It also could allow for an interpretation to appear if you needed it to be presented in a foreign language such as Spanish or Russian. By choosing a particular language, the program would alter the information so that the user would gain the most benefit. By using and constructing such a program the problems of literacy, and bilingual issues, as well as the level of reading ability can be overcome with the click of a mouse.

In a study by Thomas, Thiel, Sem, and Woermke (1995) two methods of information transfer were used to relay information about a clinical trial. the clinical trial was a research study that involved a particular type of chemotherapy protocol in certain cancer of the colon cases. The study wanted to determine if a certain medium of information transfer would generate a higher volunteer rate for the study. One method involved use of a tape recording and written format and the second method used a computer interactive software program. The study looked at three aspects, satisfaction, information understanding, and willingness to enter such a trial. The information discussed the procedures that would take place during the trial and what the patients could expect following the trial. The study showed that the patients tended to 
report a more positive attitude towards entry into the trial when they had obtained the information by the computer than those who acquired the information from traditional means.

It is important to try and make the information most accessible to the patients you will be seeing. Weiss et al (1995) also noted that among the low income elderly population studied, the number one means by which the subjects obtained their information about health and the world in general was through the television and not through written text such as a magazine or newspaper.

\section{SUMMARY}

In summary when looking at a pediatric evaluation and how to convey the results severabfactors must be taken into consideration. The first involves determining which audiological techniques will be used to obtain the results. These testing procedures will be chosen on an individual basis dependent on the child's age and cognitive skills. The second factor is to relay the information to the parents in such a way that the factual information is given as well as information that will help the parent begin to cope with the different emotions. The last issue is determining how some of the initial information can be given to the parent ahead of time so that more effective counseling can be presented after the diagnosis is made. Multimedia software appears to be a tool that can allow the audiologist to educate the parent before the evaluation about the procedures and testing protocol. Thus, leaving the parent with more time to discuss the diagnosis and the future for that child. 
CHAPTER III

\section{METHODS AND PROCEDURES}

The purpose of this study was to determine the effectiveness of a multimedia program, in conveying information regarding pediatric hearing evaluations to a general population. To accomplish this, two groups of young adults were assessed on their knowledge of basic techniques and concepts of pediatric audiology. Prior to the assessment, an experimental group viewed the program while a control group was given no specific task. While this program is ultimately aimed at use by parents, the purpose of the study was to assess the effectiveness of the program in educating a general population.

\section{SUBJECTS}

The subjects used for the study were adults ages 20 - 45. The subjects were screened to determine that no immediate family members had a hearing loss and that they had not had a hearing evaluation themselves. Subjects were chosen from students attending Portland State University and individuals from the general population. There were eighteen students and two individuals from the general population. The students were enrolled in a Speech and Hearing Science survey class, although none of the students had taken any collegelevel courses in Audiology. The two subjects from the general population were 
employed full-time and had no experience with Audiological procedures.

Subjects were randomly assigned to the control and experimental groups. In the experimental group subjects were required to demonstrate basic competency in using a computer prior to their inclusion. The participants signed a written consent allowing their answers to be used in this study.

\section{INSTRUMENTATION}

The computer program the subjects viewed was authored by Dr. Douglas Martin. The program consists of narration, digital video clips and pictures explaining various instrumentation and techniques used in a pediatric assessment. The program gave the subjects ample time to look at the information addressed and allowed them to view the program multiple times, if desired. There was no time limit places on the subjects so they could take as long as they wished to view the program. However, no subject took longer than 20 minutes. The program relayed information about what takes place in a pediatric hearing evaluation. Some of the topics that were addressed in the tutorial included: 1) Otoscopy 2) Immittance Audiometry 3) Behavioral Observation Audiometry 4) Visual Reinforcement Audiometry 5) Play Audiometry and 6) Speech testing. A narrative description of the program is provided in Appendix A. The program is interactive in the sense that the individual was able to control how quickly they went through the program and the number of times they viewed each video clip.

Viewing of the program was completed at Portland State University in the Learning Lab in Neuberger Hall. A Macintosh Centris 605 computer with a 15 inch color monitor was used to view the program. Use of the program required 
only basic manipulation of the mouse, and basic reading ability. No other peripheral devices were necessary.

An objective multiple choice test that had questions pertaining to the information discussed in the computer program, was tested for its difficulty and its accuracy. A group of students enrolled in an advanced audiology class was administered the test to determine if the questions were too difficult. One question was eliminated and a small number needed rewording. The test was administered in the written format to all subjects of both groups. The test covered information about procedures and tests shown in the computer program. The test instrument is included in Appendix B.

\section{PROCEDURES}

The subjects were randomly assigned to either the control group or the experimental group. Both groups were administered the test during their appointment time. Prior to completing the test the experimental group viewed the program at their assigned times. The test was administered immediately following the viewing of the program.

Instructions were given to each member of the experimental group describing how to use the computer program. The instructions covered how to use the mouse to manipulate the cursor and discussed the various symbols used that allowed the individual to maneuver through the program. The following verbal instructions were provided:

You will use the mouse to move ahead in the program. Click on the arrows to move forward. When you have reviewed the material and a screen comes up indicating you have reached the end of the program let the examiner know. 
Written instructions were also provided. They were presented in a narrative text on the second screen of the computer program.

Many screens contain a movie demonstrating a procedure. To view the movie simply click on the "Play" ( $>$ ) button. To move to the next screen, click on the "Next" (-->) button. 
CHAPTER IV

\section{RESULTS}

The test administered to all subjects consisted of 24 multiple-choice or trueffalse questions. The mean score for the control group was 57.7 with a standard deviation of 12.8 while the mean score for the experimental group was 76.6 with a standard deviation of 9.4. The results of a two-tailed t-test analysis showed that the experimental group score was significantly higher than the control group, $(t=-3.758 ; p=.0014)$ suggesting that viewing the program may have increased the basic knowledge of the experimental group.

\section{ITEM ANALYSIS}

An item analysis was conducted for all questions. The initial characteristic addressed in this analysis involved the questions which were answered correctly by all members of the experimental group. Table I displays the text of the questions and the frequency responses for the response options. Analysis of the control group responses for these questions revealed correct response rates around $50-60 \%$. One question (\#16) was answered by the group at a rate of $80 \%$ suggesting that the information tested in this question may very well have been common knowledge. The other questions suggest that the computer area may be strong in covering this information. 
TABLE |

\section{QUESTIONS ANSWERED CORRECTLY BY EXPERIMENTAL GROUP WITH THE FREQUENCY} DISTRIBUTION FOR EACH RESPONSE OPTION

Question (" denotes the correct response)

Control

Experimental

4) What part of the ear does tympanometry test?

$\begin{array}{lrr}\text { a) inner ear } & 4 / 10 & 0 / 10 \\ \text { b) outer ear } & 0 / 10 & 0 / 10 \\ \text { "c) middle ear } & 6 / 10 & 10 / 10\end{array}$

5) What types of problems are common with children that may affect hearing?
a) chicken pox
$4 / 10$
$0 / 10$
b) otitis media
$6 / 10$
$10 / 10$
c) poison oak
$0 / 10$
$0 / 10$

7) What procedure uses an air pump in the testing protocol?
a) otoscopy
$0 / 10$
$0 / 10$
"b) tympanometry
$6 / 10$
$10 / 10$
c) audiometry
$4 / 10$
$0 / 10$

14) Which test procedure requires no overt behavior from the child?
a) VRA
$3 / 10$
$0 / 10$
b) play audiometry
$1 / 10$
"c) tympanometry
$6 / 10$
$0 / 10$
$10 / 10$

16) Otoscopy can identify in the ear canal?
a) damage
$1 / 10$
$0 / 10$
b) foreign objects
$0 / 10$
$0 / 10$
c) ear infections
$1 / 10$
$0 / 10$
"d) all of the above
$8 / 10$
$10 / 10$

19) Which behavior might be considered a response in BOA?
*a) startle
$5 / 10$
$10 / 10$
b) raising a hand
$3 / 10$
$0 / 10$
c) pointing to a picture
$0 / 10$
$0 / 10$ 
The second characteristic looked at in the analysis regarded the questions which met the following criteria; 1) the experimental group failed to answer with $100 \%$ accuracy, 2) and a large difference (arbitrarily defined as $30 \%$ ) occurred between the two groups. Table II displays the questions meeting this criteria along with the frequency distribution for each response option. Of these questions, number $6,11,12,13$, and 15 revealed a clear tendency toward the correct answer by members of the experimental group although not all members answered correctly. For the same questions, no clear trends were evident for the control group suggesting that the program may have been effective in conveying relevant information for these areas. For question 10 , the responses indicated that the information in the program relating to this topic was at best ambiguous, because the experimental group rate did not indicate that the information had been retained.

The third characteristic examined questions in which $70 \%$ or more of the total number of subjects answered incorrectly. Table III displays the questions meeting this criteria along with a frequency distribution for each response option. All three questions showed limited differences in response trends between the experimental and control group. As there was limited difference between the groups and the total percentage incorrect was so high this result may suggest that insufficient information or time was spent on this subject in the computer program.

Table IV displays the questions and results for the questions where there were rating scores $80 \%$ or greater for both groups with a $10 \%$ difference or less between the group scores. These questions apparently appear to be either common knowledge to the subjects used in this study, or the question and 
answer were worded in a manner that showed an obvious answer with no equal alternatives.

Finally, Table $V$ displays the questions and results for the remaining questions that did not satisfy any of the previous criteria. Of the questions left one question was answered correctly by the entire control group where only $50 \%$ of the subjects in the experimental group answered correctly. A possible explanation for this occurrence, may be that some of the material in the program may have confused the subjects into answering differently. The only two true/ false questions were also in this category. One question, number 9 , appeared to be easy for both groups and the second true/ false question, number 18 , appeared to be ambiguous since there was no distinct differences in response rates between groups. The response rates for questions 9 and 18, suggest that possibly the trueffalse format does not allow the scoring to differentiate between groups due to chance, or the material in the program was confusing. The last few questions seem to have produced somewhat random responses. The material for all questions in this category should be reviewed in both the questionnaire and the interactive program. 
TABLE \|

QUESTIONS WHERE THE EXPERIMENTAL GROUP SCORED 30\% > THAN THE CONTROL GROUP WITH THE FREQUENCY DISTRIBUTION FOR EACH RESPONSE OPTION

Question ("denotes correct response)

Control

Experimental

6) What amount of hearing loss may be seen with a middle ear problem?

$\begin{array}{lll}\text { a) severe } & 3 / 10 & 0 / 10 \\ \text { b) moderately-severe } & 5 / 10 & 1 / 10 \\ \text { "c) mild } & 2 / 10 & 9 / 10\end{array}$

10) What techniques below are used on infants?

$\begin{array}{lll}\text { a) VRA } & 4 / 10 & 5 / 10 \\ \text { "b) BOA } & 2 / 10 & 5 / 10 \\ \text { c) Play audiometry } & 4 / 10 & 0 / 10\end{array}$

11) What techniques can be used on children from 3-4 months of age?

$\begin{array}{lll}\text { "a) VRA } & 4 / 10 & 7 / 10 \\ \text { b) BOA } & 4 / 10 & 3 / 10 \\ \text { c) Play audiometry } & 2 / 10 & 0 / 10\end{array}$

12) What techniques can be used on children 3 years of age?
a) VRA
$4 / 10 \quad 0 / 10$
b) BOA
$2 / 10$
$1 / 10$
"c) Play audiometry
$4 / 10$
$9 / 10$

13) Which technique gives the audiologist the most complete information regarding a child's hearing?
a) VRA
$4 / 10$
$3 / 10$
b) $B O A$
$3 / 10$
$1 / 10$
"c) Play audiometry
$3 / 10$
$6 / 10$

15) With which technique would you consider a startle to sound a response?

$\begin{array}{lll}\text { a) VRA } & 3 / 10 & 1 / 10 \\ \text { b) BOA } & 6 / 10 & 9 / 10 \\ \text { c) Play audiometry } & 1 / 10 & 0 / 10\end{array}$


TABLE III

QUESTIONS WHERE 70\% OR MORE OF THE TOTAL NUMBER OF SUBJECTS ANSWERED INCORRECTLY WITH THE FREQUENCY DISTRIBUTION FOR EACH RESPONSE OPTION

Question (*denotes correct response)

Control

Experimental

20) In tympanometry what is the basic shape of the graph that will show a normal middle ear system?
a) flat
$3 / 10$
$2 / 10$
"b) pointed
$2 / 10$
$3 / 10$
c) rounded
$5 / 10$
$5 / 10$

22) Age and language capability are used to determine what in the evaluation?
a) tympanometry settings
$0 / 10$
$0 / 10$
b) questions asked during
$2 / 10$
$1 / 10$
case history
c) techniques used to get
$5 / 10$
$6 / 10$
responses to sound
"d) materiais used to
$3 / 10$
$3 / 10$
measure speech detection
or understanding

23) Speech testing techniques are available for use on children as young as
a) 0-4 months of age
$2 / 10$
b) 4 months -3 years of age
$6 / 10$
$4 / 10$
c) older than 3 years of age
$2 / 10$
$2 / 10$
$4 / 10$ 
TABLE IV

QUESTIONS WHERE THE RATING SCORES FOR BOTH GROUPS WERE 80\% OR ABOVE WITH A 10\% DIFFERENCE OR LESS BETWEEN THE GROUPS WITH THE FREQUENCY DISTRIBUTION FOR EACHRESPONSEOPTION

Question ("denotes correct response)

Control

Experimental

3) What is the specialized flashlight that an audiologist uses to look in the ears?

$\begin{array}{lrr}\text { a) audiometer } & 0 / 10 & 0 / 10 \\ \text { "b) otoscope } & 10 / 10 & 10 / 10 \\ \text { c) tympanometer } & 0 / 10 & 0 / 10\end{array}$

8) What part of the middle ear does tympanometry test?

$\begin{array}{lll}* \text { a) eardrum movement } & 8 / 10 & 8 / 10 \\ \text { b) ear canal length } & 1 / 10 & 1 / 10 \\ \text { c) the hearing nerve } & 1 / 10 & 1 / 10\end{array}$

17) Can earphones be used on small children?

$\begin{array}{lll}\text { a) yes } & 1 / 10 & 1 / 10 \\ \text { b) no } & 1 / 10 & 0 / 10 \\ { }^{*} \text { c) sometimes depending } & 8 / 10 & 9 / 10\end{array}$

on the age of the child

21) Which of the following techniques is appropriate for use with children 6 or older?
a) BOA
$1 / 10$
$0 / 10$
b) Play audiometry
$1 / 10$
$1 / 10$
*c) Standard hand raising technique
$8 / 10$
$9 / 10$ 
TABLE V

QUESTIONS WHERE THE RESPONSES OF BOTH GROUPS MET NONE OF THE PREVIOUS CRITERIA WITHTHE FREQUENCY DISTRIBUTION OF EACH RESPONSE OPTION

Question (*denotes correct response)

Control

Experimental

1) To begin the evaluation of your child the audiologist will first?

$\begin{array}{lll}\text { "a) ask you questions } & 10 / 10 & 5 / 10 \\ \text { regarding your child } & & \\ \text { b) want to look in the child's ear } & 0 / 10 & 5 / 10 \\ \text { c) present sounds to the child } & 0 / 10 & 0 / 10\end{array}$

2) What two structures is the audiologist looking at when otoscopy is performed?
"a) the ear canal and ear drum
$8 / 10$
$6 / 10$
b) middle ear space and the
$2 / 10$
$3 / 10$
middle ear bones
c) ear wax and ear canal
$0 / 10$
$1 / 10$

9) Since the ear of a child works the same as the ear of an adult Audiologists use the same techniques to test small children that are used to test adults?
a) true
$3 / 10$
$1 / 10$
b) false
$7 / 10$
$9 / 10$

18) The audiologist chooses which technique to use strictly based on the age of the child?
a) true
b) false
$2 / 10$
$4 / 10$
$8 / 10$
$6 / 10$

24) Speech testing is used to determine?

$\begin{array}{lll}\begin{array}{l}\text { a) the softest level speech is } \\ \text { detected }\end{array} & 0 / 10 & 2 / 10 \\ \begin{array}{l}\text { b) the child's ability understanding } \\ \text { speech }\end{array} & 2 / 10 & 0 / 10 \\ \text { "c) either A or B } & 6 / 10 & 7 / 10 \\ \text { d) none of the above } & 2 / 10 & 1 / 10\end{array}$




\section{CHAPTER V}

\section{DISCUSSION}

The purpose of this study was to determine if a computer program designed to educate individuals about a pediatric evaluation would be an effective tool that could later be used in the clinic to educate parents. The statistical analysis comparing both groups showed this to be an effective tool in that the experimental group scored higher than the control group. However, when we examine the mean for both groups it can be suggested that while there may be significant difference between the groups there exists room for improvement in the experimental group's performance.

The item analysis provided information about which parts of the program may need additional work. Among these areas the information concerning speech testing techniques appeared weakest. Since the scores that related to the speech assessment were poor it can be concluded that some additions to the program showing the different speech tasks with different age groups may enhance the material covered. It would also seem important to stress that on this portion of the evaluation the child's age, be it developmental or chronological age, is no longer the only necessary characteristic of the child to consider. At this point in the testing language becomes an issue. It would be important to show in a video format not necessarily how the procedure would work but rather why it would fail to work if the language requirements were not 
met. It would then give the parents a reference if their child has difficulty with the task or the audiologist changes how the test is administered to meet the child's abilities.

Another area that was missed by a large percentage of the total subjects related to specific characteristics of tympanometry. Overall most of the information covered in the program about tympanometry was shown to be effective. However, when answering the question about the results of tympanometry, the experimental group could not remember the shape of the graph that exhibited a normal response. It is possible that the graph in the video clip was not large enough for the viewers to be able to make a distinction about specific shape. It is also possible that, since the graph in the program did not show a tympanogram with a true "point", the viewers felt the response needed to be round. It may be important to include in the program a view of not just a normal tympanogram but also those that are abnormal so the viewer can see the distinction between the graphs. It may also be necessary to identify clinically relevant names (e.g., Type A and Type B) for the comparing of tympanometric findings so that the use of the words pointed, flat, and round are not used in the question.

However, an alternative view to consider on this topic of tympanometry would be that the content was adequate for the goal of the program. Again the decision about balancing the amount of information necessary to instill a basic understanding must be considered. Although the question about tympanogram shape was missed other areas of tympanometry appeared adequate. The description of what part of the ear is measured with tympanometry, as well as information describing the air pressure pump were all proven to be effective 
aspects of the program when the response rates for those questions were examined. It may be that this represents an adequate level of knowledge for this topic. Further study will be necessary to resolve this issue.

The areas where the computer seemed to be effective were in otoscopy and BOA. Of these areas both groups seemed to do well with otoscopy. Even though the experimental group answered the question about the otoscope at $100 \%$ the control group answered it at $80 \%$. This may suggest that information about otoscopy is common knowledge and could be considered for removal from the program. However, it is an important tool in a pediatric assessment and therefore, should still be discussed within the limits of the computer program. Additionally the questions concerning puretone techniques also indicate that the program was strong in these areas. However, some of the response rates, especially in regard to VRA and Play audiometry, could use improvement. Again adding additional information concerning these areas may prove to be a benefit. It is also possible that the abbreviations of the techniques were used infrequently in the program and need to be reviewed more times before using the abbreviation alone in a question format will elicit the correct description.

It was a concern that the use of such a program may be tedious or difficult to use. The subjects appeared to have no difficulty moving through the program and expressed positive attitudes towards its content. However, a number of improvements to the program could be undertaken to provide more effective presentation of the material.

First, it may be important to have a glossary available to the viewer to enhance the interactiveness of the program and make it more efficient. The parent could simply click on one of the clinical words and a text definition would 
be made available with the addition of a text-to-speech capability, these definitions, along with all program text could be read to the individual. If this was available less questions would be asked during the process because the parent would have the answer literally at their fingertips, therefore, requiring no need for the audiologist to be present during the viewing process.

A second area of enhancement may include determining a way to have the individual who is viewing the program gain total control of how he or she moves through the program, allowing non-linear access to the information. This capability could allow the individual to review previously read material and, hopefully, improve their understanding of the material.

Finally, the program could be translated to a foreign language (including ASL) for non-English speaking individuals. By installing an interpreter program the individual could choose which language to have the presentation in. In instances where the parents are hearing impaired they could choose that the program be in sign or in written format only. By changing the format, (i.e., a narrator instead of text) we could bridge this gap in communication as well as enhance the program interactiveness.

\section{SUMMARY}

The data gathered in this study would suggest that the computer program was an effective learning tool for the subjects investigated in this study. The data would further suggest that additional research using the population of interest (i.e., parents) is warranted. However, some of the implications from the data suggest that there needs to be additional development and expansion in certain areas of the program. It is anticipated that the effectiveness of this 
program as a tool to educate would be greatly improved with the enhancements discussed above. Should additional research indicate that the program is an effective educating tool then the program could be implemented into the clinical setting. The audiologist could have parents view the program and expect some of their questions to be answered prior to the evaluation. 


\section{REFERENCES}

Atkins, D. V. (1994) Counseling children with hearing loss and their families. In Clark, J. G., Martin, F.N. (Ed.), Effective Counseling In Audiology (pp. 116 - 143). Englewood Cliffs, NJ: Prentice Hall Inc.

Clark, J. G. (1994). Audiologist's counseling purview. In Clark, J. G., Martin, F.N. (Ed.), Effective Counseling In Audiology (pp. 1 - 15). Englewood Cliffs, NJ: Prentice Hall Inc.

Hayes, D., \& Pashley, N. (1991) Assessment of infants for hearing impairment. In Jacobsen, J. T., Northern, J. L. (Ed), Diagnostic Audiology (pp.251 - 264). Austin, TX: Pro-Ed.

Hodgson, W.R. (1994) Evaluating infants and young children. In Katz, J. (Ed), Handbook of Clinical Audiology (pp.465-475). Baltimore, MD: Williams and Wilkins.

Kubler-Ross, E. (1969) On Death and Dying. New York, NY: McMillan Publishing Company.

Llewellyn-Thomas, H. A., Thiel, E. C., Sem, F., Woermke, D.E. (1995) . Presenting clinical trial information: a comparison of methods. Patient Education and Counseling, 25, 97 - 107.

Luterman, D. (1979). Counseling parents of hearing-impaired children. Boston, MA: Little, Brown and Company.

Martin, F. N., George, K. A., O'Neal, J., Daly, J.A. (1987). Audiologist's and parents' attitudes regarding counseling of families of hearing-impaired children. ASHA, (February), 27 - 32.

Martin, F. N. (1994). Conveying diagnostic information. In Clark, J. G., Martin, F.N. (Ed.), Effective Counseling in Audiology (pp. 38 - 69). Englewood Cliffs, NJ: Prentice Hall Inc.

McKerlie, D., \& Preece, J. (1993). The hype and the media: issues concerned with designing hypermedia. Journal of Microcomputer Applications, 16, $33-47$. 
Moore, J. M., Thompson, G., \& Folsom, R. C. (1992). Auditory responsiveness of premature infants utilizing visual reinforcement audiometry (VRA). Ear and Hearing, 13(3), $187-194$.

Muir D, and Field J. (1979) Newborn infants orient to sounds. Child Development, 50, 431 - 436.

Rodriguez, A.A., \& Rowe, L.A. (1995). Multimedia systems and applications Computer, 28(5), $20-22$.

Rushmer, N. (1994). Supporting families of hearing impaired infants and toddlers. Seminars in Hearing, 15 (2), $163-171$.

Silman, S., \& Silverman, C. A., (1991) Auditory Diagnosis Principles and Applications (pp. 16 -18). New York, NY: Academic Press.

Weiss, B. D., Reed, R. L., Kligman, E. W. (1995). Literacy skills and communication methods of low-income older persons. Patient Education and Counseling, 25, $109-119$. 


\section{APPENDIX A}

COMPUTER FORMAT OUTLINE 
The text of each screen of the program is shown below. The first screen is a simple title screen.

Screen 2 - Introduction

A hearing evaluation on a young child can be a confusing and frightening experience for both the child and the parent. this presentation will describe and demonstrate some of the tests that may be used to evaluate the hearing of a young child. It is hoped that by viewing this program you will fell more comfortable and knowledgeable about the evaluation your child is about to undergo. Many screens contain a movie demonstrating a procedure. To view the movie simple click on the "Play" ( $>$ ) button. To move to the next screen, click on the "Next" (-->) button.

\section{Screen 3 Otoscopy}

After talking with you a little about your child and your concerns regarding your child's hearing, the Audiologist will want to look in your child's ears. An otoscope is used for this purpose. Although some children do not care for having their ears looked at, the procedure is very simple and harmless. In performing otoscopy the Audiologist is looking for any obvious signs and damage or infection in your child's ear. Should the Audiologist have concerns regarding possible problems noted through otoscopy, you will be referred to your pediatrician or family doctor for medical evaluation.

\section{Screen 4 - Tympanometry}

Tympanometry is a test that the Audiologist will perform to evaluate the function of your child's middle ear. The middle ear is important for conducting sounds to the inner ear where the hearing nerves are located. A problem in the middle ear can cause a mild hearing loss. these types of problems are not uncommon in children (for instance, middle ear infections (otitis media) will cause this type of problem) and they often respond to medical treatment. Tympanometry involves placing a soft rubber tip into the opening of the ear canal. Small amounts of air are then pumped into the ear canal while a sound is being "bounced" off the ear drum. By measuring the amount of sound "bouncing" off of the ear drum the Audiologist can determine how well the ear drum and middle ear are working. 
Screen 5 - Audiometry Introduction

After performing tympanometry, the Audiologist will want to test your child's ability to hear different types of sounds. With an older child this type of testing simply involves asking the child to raise their hand when they hear the sound.

You have probably had your hearing tested this way. However, with very young children we often have to use some other means of measuring the hearing as these infants cannot reliably raise their hands when hearing a sound. The procedure used depends on the age of the child.

Screen 6 - Behavioral Observation Audiometry

With very young children a procedure called Behavioral Observation Audiometry $(B O A)$ is often used. With this procedure the Audiologist presents certain sounds to the child (often using common noisemakers) and watches for behaviors indicating the sound was heard. Behaviors that are watched for include head turns towards the sound, startle reactions, or decreases (or increases) in body movement or vocalizations. Although this method does not provide the amount of information a standard hearing test would provide, the Audiologist can often determine if a child's hearing is within normal limits or if there is the possibility of a hearing loss using Behavioral Observation Audiometry.

Screen 7 - Visual Reinforcement Audiometry

When the child is a little older -- at about 3-4 months or so -- a procedure called Visual Reinforcement Audiometry (VRA) is often used. With this procedure the child is placed in front speakers (or under headphones) and a sound is presented. A lighted and animated toy is displayed off to the side at the same time. After a few trials, the child learns that when the sound is heard the toy will soon light up so they turn and look for the toy. By watching for a head turn to the toy following presentation of the sound, The audiologist is able to determine which sounds the child heard and which were not heard. A skilled Audiologist can determine a great deal about a child's hearing using Visual Reinforcement Audiometry.

Screen 8 - Play Audiometry

While BOA and VRA can provide valuable information regarding an infants hearing, older children can perform tasks which will provide the Audiologist with a more complete picture of the child's hearing. By about 3 years of age most children can be tested using play audiometry. In play audiometry, a game such 
as dropping a block in a bucket or placing pieces in a puzzle is 'played' whenever the child hears the sound. A complete audiogram describing a child's hearing can be obtained using play audiometry. At about 5 or 6 years of age, most children can be tested using standard hand-raising techniques as are typically used with adults.

Screen 9 - Speech Audiometry

In addition to testing using tones, Audiologists often use speech tests as part of the evaluation. Speech tests are used to determine the softest level at which a child may recognize speech or how well a child can understand speech presented at normal conversational levels. For even the youngest infant, speech can be used to test the child's sensitivity to sounds. Speech is particularly well suited to this task as infants, as well as older children, are much more responsive to human speech than other non-speech sounds. As a child's vocabulary expands with age more meaningful speech signals can be used for testing. The particular speech task used will depend on the age and language capabilities of the child.

Screen 10 - Conclusion

This concludes the presentation. If you have any questions please feel free to ask the Audiologist who will be working with you.

Click the "Quit" button when you are ready to leave the program. 
APPENDIX B

EXAMPLE SCREEN FROM THE PROGRAM 
With very young children a procedure called Behavioral Observation Audiometry (BOA) is often used. With this procedure the Audiologist presents certain sounds to the child (often using common noisemakers) and watches for behaviors indicating the sound was heard. Behaviors that are watched for include head turns towards the sound, startle reactions, or decreases (ort) increases) in body movement 6 ? vocalizations. Although this mes.

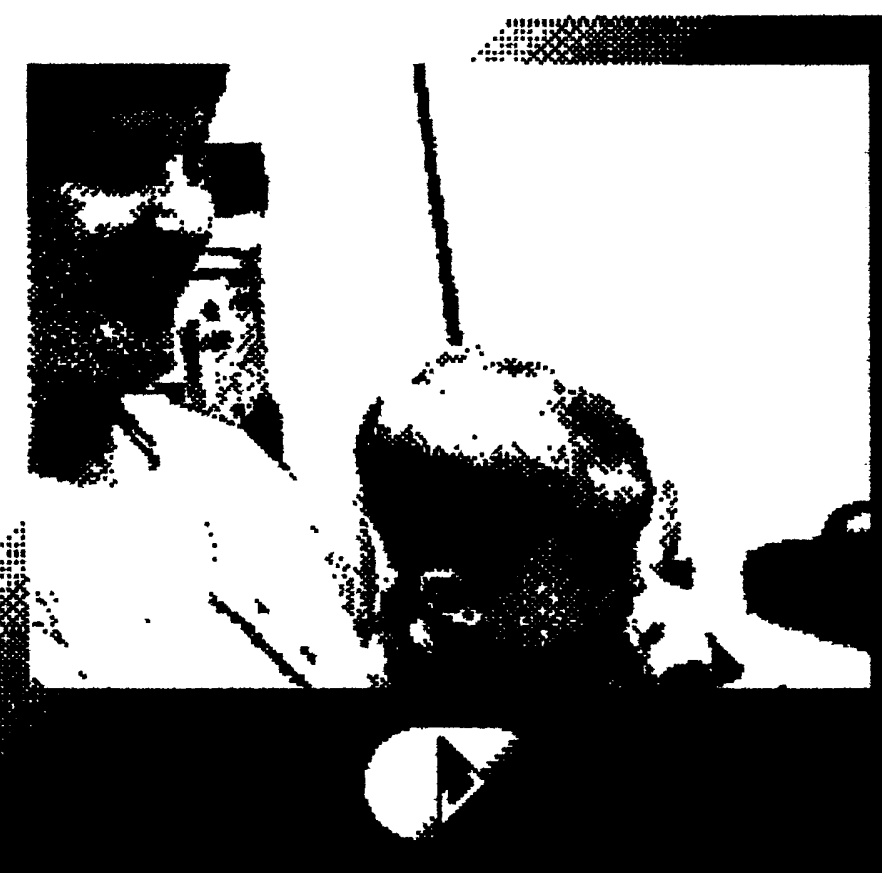
does not provide the amgly. information a standard here would provide, the Audioly determine if a child'st's. normal limits or if the of a hearing lo Observatt 
APPENDIX C

QUESTIONNAIRE 
Group:

S No:

1) To begin the evaluation of your child the audiologist will first?

${ }^{\star} A$ ) ask you questions regarding your child

B) want to look in the child's ear

C) present sounds to the child

2) What two structures is the audiologist looking at when otoscopy is Performed?

${ }^{\star}$ A) the ear canal and ear drum

B) middle ear space and middle ear bones

C) ear wax and ear canal

3) What is the specialized flashlight that an audiologist uses to look in the ears?
A) audiometer
*B) otoscope
C) tympanometer

4) What part of the ear does tympanometry test?
A) inner ear
B) outer ear
${ }^{\star}$ C) middle ear

5) What types of problems are common with children that may affect hearing?
A) chicken pox
$\left.{ }^{\star} B\right)$ otitis media
C) poison oak

6) What amount of hearing loss may be seen with a middle ear problem?
A) severe
B) moderately-severe
${ }^{\star}$ C) mild

7) What procedure uses an air pump in the testing protocol?
A) otoscopy
*B) tympanometry
C) audiometry 
8) What part of the middle ear does tympanometry test?
$\left.{ }^{\star} A\right)$ eardrum movement
B) ear canal length
C) the hearing nerve

9) Since the ear of a child works the same as the ear of an adult,

Audiologists use the same techniques to test small children that are used to test adults?
A) true
$\left.{ }^{*} B\right)$ false

10) What techniques below are used on infants?
A) VRA
*B) $B O A$
C) Play audiometry

11) What techniques can be used on children from 3-4 months of age?
$\left.{ }^{*} A\right)$ VRA
B) $B O A$
C) Play audiometry

12) What techniques can be used on children 3 years of age?
A) VRA
B) BOA
${ }^{*}$ C) Play audiometry

13) Which technique gives the audiologist the most complete information regarding a child's hearing?
A) VRA
B) $B O A$
${ }^{*}$ C) Play audiometry

14) Which test procedure requires no overt behavior from the child?
A) VRA
B) Play audiometry
*C) Tympanometry

15) With which technique would you consider a startle to sound as a response?
A) VRA
*B) BOA
C) Play audiometry 
16) Otoscopy can identify in the ear canal?
A) damage
B) foreign objects
C) ear infections
${ }^{\star} D$ ) all of the above

17) Can earphones be used on small children?
A) yes
B) no
$\left.{ }^{*} \mathrm{C}\right)$ sometimes depending on the age of the child

18) The audiologist chooses which technique to use strictly based on the age of the child?
A) true
${ }^{\star}$ B) false

19) Which behavior might be considered a response in BOA?
*A) startle
B) raising a hand
C) pointing to a picture

20) In tympanometry what is the basic shape of the graph that will show a normal middle ear system?
A) flat
*B) pointed
C) rounded

21) Which of the following techniques is appropriate for use with children 6 or older?
A) $\mathrm{BOA}$
B) Play audiometry
${ }^{\star}$ C) Standard hand raising technique
D) materials used to measure speech detection or understanding

22) Age and language capability are used to determine what in the evaluation?
A) tympanometry settings
B) questions asked during case history
C) techniques used to get responses to sound
${ }^{*}$ D) materials used to measure speech detection of understanding 
23) Speech testing techniques are available for use on children as young a
A) 0-4 months
B) 4 months - 3 years of age
C) older than 3 years of age

24) Speech testing is used to determine?
A) the softest level speech is detected
$B)$ the child's ability understanding speech
$\left.{ }^{*} \mathrm{C}\right)$ either A or B
D) none of the above 


\section{APPENDIX D}

INFORMED CONSENT FORM 


\section{PORTLAND STATE UNIVERSITY INFORMED CONSENT}

1) 1 the questionnaire administered to me, by Jeanne Aleskus project pursuant to a Master's thesis.

2) I understand that this study involves completing a questionnaire once or using a computer program and then answering the questionnaire, during one visit to the clinic. Both the questionnaire and the computer program pertain to pediatric hearing evaluations. The time for completing the questionnaire and viewing the computer program will take approximately 20-25 minutes.

3) It has been explained to me that the purpose of the study is to learn if the computer program would be a useful tool to be used in the clinic during precounseling.

4) It is understood that there will be no direct benefits to me by allowing my questionnaire to be included in the study, nor are there any risks to me associated with this study.

5) I have been given the opportunity to ask questions of the researcher about the study.

6) I understand that participation is of a voluntary nature and the decision regarding whether to participate will not affect my relationship with the PSU Audiology Clinic or any other person or agency.

7) I understand that the results of my evaluation will be confidential and that my name will not be associated with the test results and in any reports.

I have read and understand the foregoing information and agree to participate in this study.

Date:

Signature:

If you have any concerns and questions about this study, please call the Chair of Human Subjects Research and Review committee at 725-3417. 